\title{
UBER DIE DURCH PILZE VERURSACHTE WELKE AN CLARKIA
}

\author{
AnNa-Lisa Ruokola \\ Pflanzenpathologisches Institut der Universität Helsinki
}

Eingegangen am 6. V. 1960

In einem Hausgarten auf dem Versuchsgut Viik der Universität Helsinki wurden Anfang August 1958 an Clarkia elegans Dougl. in reichlichem Masse Welkesymptome beobachtet. Einige Clarkien, die mit ihrer Blüte begonnen hatten, waren dann schon verwelkt. Das noch am Leben gewesene Blattwerk anderer Pflanzen war beträchtlich gerötet und an den Spitzen erschlafft. Der Ansatzteil ihres Stengels wies eine Beschädigung auf, in der ein Pilzmyzel zu sehen war; das Innere des Stengels war an dieser Stelle gebräunt. Das Pilzmyzel breitete sich teilweise auch in die Wurzeln der Pflanzen aus. In kranken Pflanzen fanden sich FusariumKonidien und Botrytis-Konidienträger nebst Konidien.

Als die Pilze in Petrischalen auf Agarnährboden übertragen und Artbestimmungen angestellt wurden, ergaben sich als ihre Arten Fusarium poae (Peck) Wr. (vgl. 3) und Botrytis cinerea Pers. (vgl. 5). Ihr pathogener Charakter wurde in zwei Laboratoriumsversuchen erforscht, bei denen Clarkia in Tontöpfen a) auf Mull, den man an einer Wuchsstelle kranker Pflanzen im Garten entnommen hatte, und b) auf gereinigtem Mull erzogen hatte. Autoklavisierter Mull konnte bei den Versuchen nicht benutzt werden, weil sich an seiner Oberfläche in reichlichem Masse verschiedener Schimmel bildete. Daher wurde reiner Mull in einem Geschäft gekauft; er war als desinfiziert angegeben und wurde in Kunststoffbeuteln verpackt verkauft.

Die Clarkien, die auf dem an der Wuchsstelle von Clarkia im Garten entnommenen nichtdesinfizierten Mull erzogen wurden, erkrankten ohne Infizieren (s. Tabelle); an ihnen erschienen $B$. cinerea und $F$. poae. Bei Versuch 2 liessen sich von den erkrankten Pflanzen ausserdem $F$. orthoceras App. \& Wr. und $F$. redolens Wr. isolieren (7; vgl. auch 1-3); diese Arten sind von Snyder \& Hansen (6) der Art F. oxysporum Schl. emend. Snyder \& Hansen angeschlossen worden.

In Versuch 1, bei dem alle Versuchsgefässe in demselben Raum untergebracht waren, erschien B. cinerea auch an Pflanzen, deren Standboden ursprünglich keine Pilzschädlinge enthalten hatte. Daher wurden bei Versuch 2 die infizierten Bestände in einen anderen Raum gestellt als die nichtinfizierten, woneben sicherheitshalber 


\begin{tabular}{cccccc}
\hline \multirow{3}{*}{ Mull } & $\begin{array}{c}\text { Auf Mull } \\
\text { übertra- } \\
\left.\text { gen }^{1}\right)\end{array}$ & $\begin{array}{c}\text { Zahl der } \\
\text { Pflanzen } \\
\text { am Uber- } \\
\text { tragungs- } \\
\text { tag }\end{array}$ & $\begin{array}{c}\text { Infi- } \\
\text { ziert }\end{array}$ & $\begin{array}{c}\text { Gesund- } \\
\text { heit der } \\
\text { Pflanzen }\end{array}$ & $\begin{array}{c}\text { Beobachtete } \\
\text { Pilzarten }\end{array}$ \\
& St. & $\left.(0-3)^{2}\right)$ & \\
\hline
\end{tabular}

Versuch 1 .

Am 10. 9. 1958 gesät. Samen ungebeizt. 2 Wiederholungen.

Temperatur $18.6^{\circ} \mathrm{C}$. Belichtung am Tage ca. 8000 Lux, nachts (bis zum 17. 10.) ca. 1200 Lux.

$\begin{array}{ccccccc} & & 17.10 . & 26.10 . & 14.11 . & 26.10 . & 14.11 . \\ \text { Gesäubert } & - & 13 & 0 & 3 . & 3.0 & 2.4 \text { B. cinerea } \\ -,- & \text { B. cinerea } & 12 & 9 & 11 & 1.3 & 0.5 \text { B. cinerea } \\ - \text { - }- & \text { F. poae } & 11 & 10 & 11 & 1.8 & 0.0 \text { F. poae } \\ \text { Aus dem Garten } & - & 12 & 1 & 3 & 2.9 & 2.3 \text { B. cinerea, F. poae }\end{array}$

Versuch 2 .

Am 3. 7. 1959 gesät. Der Samen mit Ceresan-Nassbeizstoff gebeizt. 3 Wiederholungen. Temperatur $26.0^{\circ} \mathrm{C}$. Belichtung mittags ca. 30000 Lux.

\begin{tabular}{|c|c|c|c|c|c|c|c|}
\hline Gesäubert & - & $\begin{array}{c}15.8 . \\
36\end{array}$ & $\begin{array}{c}22.8 . \\
0\end{array}$ & $\begin{array}{c}26.8 . \\
0\end{array}$ & $\begin{array}{c}22.8 . \\
3.0\end{array}$ & $\begin{array}{c}26.8 . \\
3.0\end{array}$ & - \\
\hline,-- & B. cinerea & 36 & 11 & 36 & 2.3 & 0.8 & B. cinerea \\
\hline,-- & F. poae & 36 & 20 & 36 & 2.0 & 0.4 & F. poae \\
\hline Aus dem Garten & - & 36 & 26 & 35 & 0.9 & 0.3 & $\begin{array}{l}\text { B. cin., F. poae und } \\
\text { andere Fusarium- } \\
\text { Arten }\end{array}$ \\
\hline
\end{tabular}

1) Auf die Oberfläche des Mulls wurde Pilzaufschwemmung gegossen: Versuch 1 am 10.9. und 17. 10.; Versuch 2 am 15. 8. Die Pflanzen wurden mit Glasglocken überdeckt.

$\left.{ }^{2}\right) \mathbf{3}=$ die Pflanzen ganz gesund; $0=$ abgestorben.

das Saatgut gebeizt wurde. Die auf dem im Geschäft gekauften reinen Mull erzogenen Pflanzen erhielten sich dann während der ganzen Versuchszeit völlig gesund.

Das Impfen der Wuchsunterlage mit Pilzen bewirkte in beiden Versuchen eine Infektion; von den Pflanzen liess sich die Pilzart (B. cinerea bzw. F. poae) isolieren, die dem Mull eingeimpft worden war.

In Kanada hat man $F$. oxysporum und $F$. solani (Mart.) App. \& Wr. emend. Snyder \& Hansen vom Stengelansatz welkekranker Clarkien isoliert (2). LewIS (4) hat durch Infektionsversuche B. cinerea und Fusarium sp. als für Clarkia pathogen erwiesen. In ihren Versuchen befiel B. cinerea ausser dem Stengel auch Blätter, Fusarium sp. nur den Stengel.

In dem von uns untersuchten Fall befielen sowohl B. cinerea als $F$. poae in Laboratoriumsversuchen, bei denen die Luft unter der Glasglocke feucht blieb, Stengel wie auch Blätter von Clarkien. Dagegen erschienen im Garten diese Pilze nur am Ansatzteil des Stengels, nahe der Erdoberfläche, wo die Luft am feuchtesten ist. In dem Garten war Clarkia an derselben Stelle seit 1945 gezogen worden, aber die Krankheit erschien an ihr auffallend nur in dem feuchten Sommer 1958 (Nieder- 
schlagsmenge im Juli $89.0 \mathrm{~mm}$, Temperaturmittel dann $15.6^{\circ} \mathrm{C}$ ). In dem trockenen Sommer 1959 (Niederschlagsmenge im Juli $65.0 \mathrm{~mm}$, Temperaturmittel dann $19.1^{\circ} \mathrm{C}$ ) ist die Krankheit bei Clarkia überhaupt nicht vorgekommen, obgleich der Boden einen reichlichen, agressiven B. cinerea- und Fusarium-Bestand enthielt (Versuch 2).

\section{$Z$ us a m me $n$ fas $u n g$}

In dem regnerischen Sommer 1958 erschien an im Garten gewachsener Clarkia ein Welken, das zum Verkümmern und Absterben der Pflanzen führte. Am Ansatz der Stengel zeigte sich eine Beschädigung. Aus ihr wurden Botrytis cinerea Pers. und Fusarium poae (Peck) Wr. isoliert.

Bei den im Laboratorium ausgeführten Versuchen infizierten diese Pilzarten Clarkia. Doch scheint es, dass sie im Freiland an Clarkia bedeutenden Schaden nur dann anrichten können, wenn die Feuchtigkeit der Luft grösser als normalerweise ist.

\section{SCHRIFTTUM}

(1) Gordon, W. L. 1952. The occurrence of Fusarium species in Canada. Rep. Canad. J. Bot. 30: $209-251$.

(2) - - 1959. The occurrence of Fusarium species in Canada. Ibid. 37: 257-290.

(3) Jamalainen, E. A. 1943-1944. Úber die Fusarien Finnlands. II-III. Staatl. Landw. Versuchstät. Veröff. 123, 124. Helsinki.

(4) Lewis, E. A. 1937. Some fungous diseases of Clarkia elegans. Phytop. 27: 951-953.

(5) Lindau, G. 1907. Fungi imperfecti: Hyphomycetes (erste Hälfte) 8: 284-289. Rabenhorst's Kryptogamen-Flora (2. Aufl. 1. Band). Leipzig.

(6) Snyder, W. C. \& Hansen, H. N. 1940. The species concept in Fusarium. Amer. J. Bot. 27: 64-67.

(7) Wollenweber, H. W. \& Reinking, O. A. 1935. Die Fusarien, ihre Beschreibung, Schadwirkung und Bekämpfung. 355 pp. Berlin.

S E L O T U S :

SIENIEN AIHEUTTAMASTA KLARKIAN NUUTUMISESTA

ANNA-LiIsA RUOKOLA

Yliopiston kasvipatologian laitos, Helsinki

Sateisena kesãnä 1958 esiintyi puutarhassa kasvaneessa klarkiassa nuutumista, joka johti kasvien surkastumiseen ja kuolemiseen. Varsien tyvessä oli vioittuma. Siitä eristettiin Botrytis cinerea Pers. ja Fusarium poae (Peck) Wr.

Laboratoriossa suoritetuissa kokeissa nämä sienilajit saastuttivat klarkiaa. Näyttää kuitenkin siltä, että ne ulkona voivat klarkiassa aiheuttaa huomattavaa tuhoa ainoastaan silloin kun ilman kosteus on normaalista suurempi. 